\title{
Staphylococcus aureus related to bovine mastitis in Switzerland: Clonal diversity, virulence gene profiles, and antimicrobial resistance of isolates collected throughout 2017
}

\author{
N. Käppeli, M. Morach, S. Corti, C. Eicher, R. Stephan, and S. Johler* \\ Institute for Food Safety and Hygiene, Vetsuisse Faculty University of Zurich, 8057 Zurich, Switzerland
}

\section{ABSTRACT}

Staphylococcus aureus can be associated with subclinical, acute, chronic, and toxic cases of bovine intramammary infections, leading to considerable financial losses for the dairy industry in Switzerland and worldwide. In addition, milk products are one of the most common food categories implicated in staphylococcal food poisoning in humans. Detailed information on the population structure, as well as the virulence and resistance characteristics of Staph. aureus originating from bovine mastitis milk is needed to allow for source attribution and risk assessment of Staph. aureus in a food poisoning context and to improve therapeutic approaches in cattle. Our objective was to assess the population structure, phenotypic resistance patterns, and virulence and resistance gene profiles of Staph. aureus isolates from bovine mastitis milk in Switzerland. To this end, 58 Staph. aureus strains were characterized. The DNA microarray was used to test for the presence or absence of virulence and resistance genes. In addition, minimum inhibitory concentrations of various antimicrobial agents were determined by microdilution. To assess the population structure of the isolates, we determined clonal complexes (CC) using DNA microarray hybridization profiles and performed multilocus sequence typing and spa typing. The strains were assigned to 7 clonal complexes, 10 sequence types, and 11 spa types, with CC705 (43\%), CC97 (33\%), and CC20 (12\%) representing the most common lineages and t529 (43\%) and t267 (21\%) representing the most common spa types. Only 1 isolate was assigned to CC8, a clonal lineage linked to high within-herd prevalence of mastitis. A total of $14 \%(n=8)$ of strains were classified as resistant to penicillin, and 1 strain each was classified as oxacillin and pirlimycin resistant. Although

Received July 2, 2018.

Accepted December 23, 2018.

*Corresponding author: sophia.johler@uzh.ch no clinical breakpoints are available for the combination of kanamycin/cefalexin, growth of all strains was inhibited by the lowest combination of kanamycin/ cefalexin concentrations tested $(4 \mu \mathrm{g} / \mathrm{mL}$ of kanamycin and $0.4 \mu \mathrm{g} / \mathrm{mL}$ of cefalexin). One strain assigned to CC20, ST389, and t2094 exhibited resistance to penicillin, oxacillin, and pirlimycin as well as intermediate susceptibility to erythromycin and high minimum inhibitory concentration for several antimicrobial agents, for which no breakpoints were available.

Key words: Staphylococcus aureus, bovine mastitis, minimum inhibitory concentration, population structure

\section{INTRODUCTION}

The dairy industry suffers from considerable economic losses due to staphylococcal mastitis in cattle (Wells et al., 1998), with the prevalence of udder infections being closely linked to milking hygiene, as well as udder and leg hygiene (Neave et al., 1969; Schreiner and Ruegg, 2003). Intramammary infections caused by Staphylococcus aureus are difficult to cure and are particularly challenging, as they are prone to chronicity and resurgence (Peton and Le Loir, 2014). Though antibiotic treatment is widely used to fight bovine mastitis, its merits are controversial. Use of antimicrobial agents is not only economically questionable and favors the development of antibiotic resistance, but it is also unsuitable to address the issue of intracellular persistence of the organism (Steeneveld et al., 2011; Fluit, 2012; Saini et al., 2012). Therefore, increased efforts are now focused on the development of vaccines. Recent studies suggested extended characterization of the genetic background of bovine mastitis isolates could enable identification of proteins crucial for colonization and infection that might serve as biomarkers in the identification of vaccine targets (Fluit, 2012; Klein et al., 2012). It has been argued that knowledge of local epidemiology is also essential for antimicrobial treatment choices in the absence of susceptibility data (Sakwinska et al., 2011b), as closely related strains frequently share resistance gene patterns. For instance, 
previous publications indicate that isolates of clonal complex (CC) 705, CC479, and CC20 are only very rarely classified as resistant to antimicrobial agents used to treat bovine mastitis (Sakwinska et al., 2011b; Moser et al., 2013). Therefore, further data are needed to either corroborate or relativize such findings.

Bovine intramammary Staph. aureus infections are also of relevance in the context of food-borne intoxications in humans. Ingestion of food containing staphylococcal enterotoxins leads to staphylococcal food poisoning characterized by violent vomiting, diarrhea, and prostration (Fetsch and Johler, 2018). Although food handlers contaminating food with Staph. aureus are considered the most common source of staphylococcal food poisoning, outbreaks have also been linked to consumption of raw milk or raw milk cheese originating from dairy animals suffering of mastitis (Giezendanner et al., 2009; Johler et al., 2015). The objective of our study was to assess the population structure, phenotypic and genotypic resistance patterns, and virulence and resistance gene profiles of Staph. aureus isolates from bovine mastitis milk in Switzerland to provide data needed to improve treatment of bovine mastitis.

\section{MATERIALS AND METHODS}

\section{Bacterial Isolation and Species Identification}

Samples were submitted by the ambulatory veterinary service of the farm animal clinic of University of Zurich to the routine diagnostic laboratory of the Institute for Food Safety and Hygiene, University of Zurich (January 2017 to January 2018). A total of 58 milk samples originating from 58 different cows and 38 farms, with the vast majority of farms being located in the canton of Zurich (30 out of 38 farms), were included in the study. Information on the geographical origin of the samples, the farm, and (if available) on California mastitis test results and the type of mastitis diagnosed are provided in Supplemental Table S1 (https://doi .org/10.3168/jds.2018-15317).

Bacteriological examinations of the milk samples were performed according to standard procedures (National Mastitis Council, 1999). Species identification was performed by MALDI-TOF spectrometry (Bruker BioSpin AG, Fällanden, Switzerland) according to the manufacturer's instructions.

\section{DNA Extraction}

The DNA isolation was performed following the protocol suggested by the DNA microarray provider (StaphyType ArrayStrips, Alere/Abbott Laboratories, Jena, Germany) using extraction kits supplied by Qia- gen (Hilden, Germany). A Nanodrop ND-1000 UV/Vis spectrophotometer (NanoDrop Technologies, Wilmington, DE) was used to determine the concentration of nucleic acids.

\section{Multilocus Sequence Typing}

Multilocus sequence typing (MLST) was performed with all strains using the GoTaq PCR system (Promega AG, Dübendorf, Switzerland) and primers and cycling conditions previously described (Enright et al., 2000). Briefly, target regions of arcC, aroE, glpF, gmk, $p t a, t p i$, and yqiL were amplified, PCR products were subsequently purified, and sequencing was outsourced (Microsynth, Balgach, Switzerland). The allelic profile of each strain was identified and assigned to the respective sequence type (ST) using the PubMLST database (https://pubmlst.org).

\section{spa Typing}

The polymorphic X region of the spa gene was determined for all strains using spa-1113f (5'-TAAAGACGATCCTTCGGTGAGC- $3^{\prime}$ ) and spa-1514r primers (5'-CAGCAGTAGTGCCGTTTGCTT-3'; Aires-deSousa et al., 2006) and the GoTaq PCR system (Promega AG), as previously described (Wattinger et al., 2012). The PCR amplicons were purified using the MinElute PCR Purification Kit (Qiagen) and sequencing was outsourced (Microsynth). Subsequently, spa types were determined using the $s p a$-server (http://spa .ridom.de/; Harmsen et al., 2003).

\section{DNA Microarray-Based Genotyping, CC Prediction, and SplitsTree Analysis}

The presence or absence of $>300$ genes and allelic variants was assessed for all strains using StaphyType ArrayStrips (Alere/Abbott Laboratories) according to the manufacturer's instructions that have been described by Monecke et al. (2008). Multiplex linear DNA amplification and microarray hybridization enables identification of species markers, genes conferring resistance to antimicrobial agents, and virulence determinants, such as genes encoding enterotoxins, leukocidins, hemolysins, and microbial surface components recognizing adhesive matrix molecules. The microarray also predicts assignment of strains to clonal complexes. The DNA microarray profiles were converted to sequence-like strings, as previously described (Wattinger et al., 2012), to enable visualization using SplitsTree, a software package designed to compute unrooted phylogenetic networks from molecular sequence data (Huson and Bryant, 2006). 


\section{Susceptibility Testing}

Minimum inhibitory concentrations of various antimicrobial agents were determined for all 58 isolates by microdilution using the Micronaut-S Mastitis 3 system (Merlin, Bornheim-Hersel, Germany) in accordance with the manufacturer's instructions. The test system includes the following antimicrobial agents: penicillin (0.125-8 $\mu \mathrm{g} / \mathrm{mL})$, ampicillin $(4-16 \mu \mathrm{g} / \mathrm{mL})$, cefazolin (4-32 $\mu \mathrm{g} / \mathrm{mL})$, cefoperazone $(2-16 \mu \mathrm{g} / \mathrm{mL})$, cefquinome (1-8 $\mu \mathrm{g} / \mathrm{mL})$, oxacillin $(1-4 \mu \mathrm{g} / \mathrm{mL})$, pirlimycin (1-4 $\mu \mathrm{g} / \mathrm{mL})$, erythromycin $(0.125-4 \mu \mathrm{g} / \mathrm{mL})$, marbofloxacin $(0.25-4 \mu \mathrm{g} / \mathrm{mL}$ ), amoxicillin/clavulanic acid (from $4 \mu \mathrm{g} / \mathrm{mL}$ of amoxicillin and $2 \mu \mathrm{g} / \mathrm{mL}$ of clavulanic acid to $32 \mu \mathrm{g} / \mathrm{mL}$ of amoxicillin and $16 \mu \mathrm{g} / \mathrm{mL}$ of clavulanic acid), and kanamycin-cefalexin (from $4 \mu \mathrm{g} / \mathrm{mL}$ of kanamycin and $0.4 \mu \mathrm{g} / \mathrm{mL}$ of cefalexin to $32 \mu \mathrm{g} / \mathrm{mL}$ of kanamycin and $3.2 \mu \mathrm{g} / \mathrm{mL}$ of cefalexin).

\section{RESULTS}

Species confirmation of all 58 isolates identified as Staph. aureus by MALDI-TOF MS was achieved using DNA microarray species markers. To avoid bias, the collection was screened for isolates representing the same strain by comparison of all features tested, including microarray profiles and resistance patterns, and all isolates were found to represent unique strains. The strains were assigned to $7 \mathrm{CC}, 10 \mathrm{ST}$, and 11 spa types. The most common clonal lineages were CC705 (formerly CC151; 43\%), CC97 (33\%), and CC20 (12\%). Strains were only rarely assigned to CC1 (3\%), CC479 (5\%), CC8 (2\%), and CC15 (2\%). The most common spa types were t529 (43\%) and t267 (21\%), followed by t524 (9\%) and t2094 (7\%). An overview of the typing data is provided in Table 1 and comprehensive information can be found in Supplemental Table S1 (https:// doi.org/10.3168/jds.2018-15317).

For 10 of the farms included in the study, more than 1 isolate was available and 3 farms had known Staph. aureus mastitis problems at the herd level (see Table 2 ). An overview of the CC, ST, and spa types associated with these isolates is presented in Table 2. A SplitsTree was used to construct an unrooted phylogenetic network depicting relatedness of all isolates based on similarity of DNA hybridization profiles (see Figure 1). All strains assigned to the same CC formed clusters in the SplitsTree. Strains that originated from the same herd were color-coded.

Virulence and resistance gene profiles of all strains were determined by DNA microarray. Whereas none of the strains carried mecA/mecC associated with methicillin-resistant Staph. aureus, NK_7 (CC8, ST8, t2953) harbored cassette chromosome recombinase genes $\mathrm{crr} A$ and $\operatorname{crr} B$. In addition, we detected the fosfomycin resistance gene, fos $B$, which encodes a metallothiol transferase. The tst gene was detected in 7 out of 25 strains assigned to CC705. None of the strains was positive for the genes encoding exfoliative toxins associated with staphylococcal scalded skin syndrome or carried genes coding for epidermal cell differentiation inhibitors.

A microdilution approach was chosen to determine the susceptibility of all 58 strains to different antimicrobial agents. An overview of resistance phenotypes and the MIC at which $\geq 50$ and $\geq 90 \%$ of the strains tested in our study would be inhibited is presented in Table 3 and Figure 2. Comprehensive data on MIC distribution are available in Supplemental Figure S1 (https://doi .org/10.3168/jds.2018-15317). For 8 of the antimicrobial agents tested, no breakpoints were available. For

Table 1. Overview of typing and characterization results, sorted by frequency of occurrence

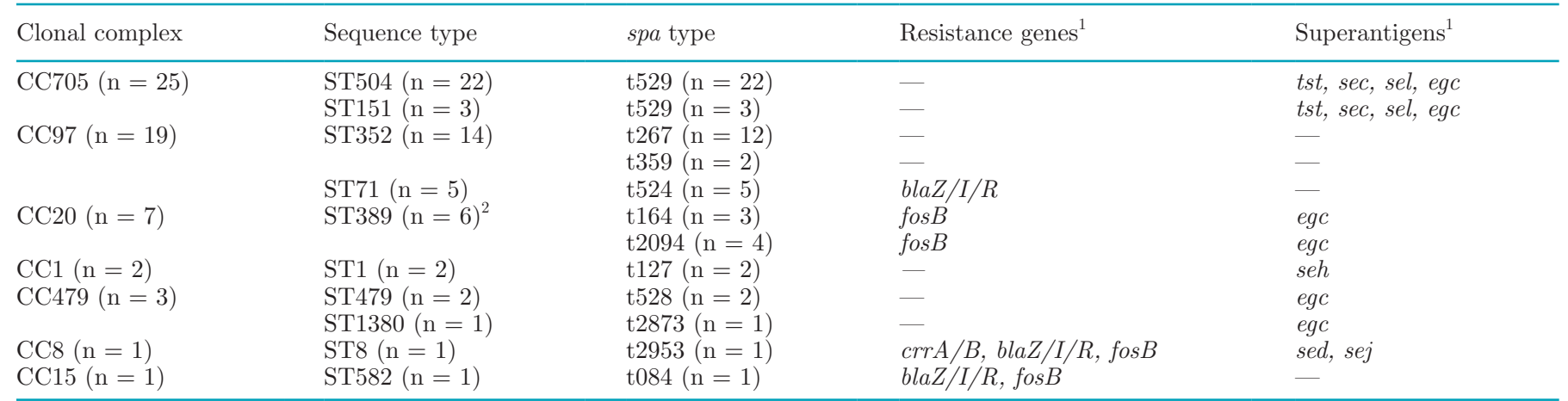

\footnotetext{
${ }^{1}$ The presence of selected resistance and virulence genes determined by DNA microarray is stated. Genes encoding resistance determinants and superantigens were present in at least 1 of the strains of this clonal complex/sequence type/spa type combination. For a full report of all microarray data for each single strain, see Supplemental Table S1 (https://doi.org/10.3168/jds.2018-15317). None of the isolates harbored mecA/mecC characteristic for methicillin-resistant Staphylococcus aureus, pvl encoding Panton-Valentine leukocidin, or genes encoding exfoliative toxins.

${ }^{2}$ One strain could not be assigned.
} 
penicillin, oxacillin, erythromycin, and kanamycin/cefalexin, human clinical breakpoints were used. Fourteen percent $(n=8)$ of strains were classified as resistant to penicillin, and 1 strain each was classified as resistant to oxacillin and pirlimycin. Growth of all strains was inhibited by the lowest combination of kanamycin/ cefalexin concentrations tested $(4 \mu \mathrm{g} / \mathrm{mL}$ of kanamycin and $0.4 \mu \mathrm{g} / \mathrm{mL}$ of cefalexin). No clinical breakpoints were available for ampicillin, cefazolin, cefoperazone, cefquinome, or marbofloxacin, and no clinical breakpoints were available for amoxicillin/clavulanic acid. With 1 exception, all isolates yielded MIC of $\leq 4$ and $\leq 2 \mu \mathrm{g} /$ $\mathrm{mL}$, which represented the lowest concentration tested. Only for 1 strain (NK_18), a higher MIC was determined for this combination of antimicrobial agents (32 $\mu \mathrm{g} / \mathrm{mL}$ of amoxicillin and $16 \mu \mathrm{g} / \mathrm{mL}$ of clavulanic acid). Strain NK_18 exhibited resistance to penicillin, oxacillin, and pirlimycin as well as intermediate susceptibility to erythromycin and high MIC for several antimicrobial agents for which no breakpoints were available: cefazolin MIC >32, erythromycin MIC >0.5, amoxicillin/ clavulanic acid MIC >16/8, and marbofloxacin MIC $>0.25$. Strain NK_18 was assigned to CC20, ST389, and t2094 and originated from a farm for which only 1 milk sample was submitted (F14). The milk sample was collected from a cow with subclinical mastitis and a positive California mastitis test in mid lactation. We included 3 farms in the study for which herd problems with Staph. aureus mastitis are known. For 1 of these farms (F11), a Staph. aureus of the same CC, ST, and spa type (CC20, ST389, t2094) as NK_18 was detected that was susceptible to all tested antimicrobial agents.

\section{DISCUSSION}

None of the strains in our study were detected more than once. In total, $7 \mathrm{CC}$ were predicted by DNA microarray and further differentiated by MLST and spa typing into $10 \mathrm{ST}$ and 11 spa types. Whereas spa typing yielded overall higher resolution than MLST, the most common bovine spa type (t529) could be subdivided into 2 sequence types (ST504 and ST151). The most prevalent clonal lineages in this study were CC705 (former CC151) and CC97. These CC are frequently detected in Staph. aureus collected from cases of bovine IMI in Switzerland and worldwide (Johler et al., 2011; Sakwinska et al., 2011a; Fitzgerald, 2012; Moser et al., 2013; Stalder et al., 2014; Boss et al., 2016). Clonal complex 705 is the major clone detected among Staph. aureus associated with bovine mastitis and was reported to occur exclusively in the bovine host (Sakwinska et al., 2011a; Fitzgerald, 2012; Boss et al., 2016). In contrast, CC97 strains, which were assigned to the spa types t267 and t359 also detected in our study, were linked to infections with methicillinresistant Staph. aureus (MRSA) in humans (Ellington et al., 2008). The MRSA isolates from wound infection and cellulitis cases in humans carried enterotoxin genes sed and sej (Ellington et al., 2008), which were missing in methicillin-susceptible Staph. aureus isolates from cattle included in this study. Clonal complex 20 is not exclusively linked to mastitis in cattle (Hasman et al., 2010). This clonal lineage causes also infections in humans (Luedicke et al., 2010; Wattinger et al., 2012) and was reported to be significantly associated with

Table 2. Overview of clonal complexes (CC), sequence types (ST), and spa types for isolates either originating from the same herd or linked to farms with known Staphylococcus aureus mastitis problems at herd level

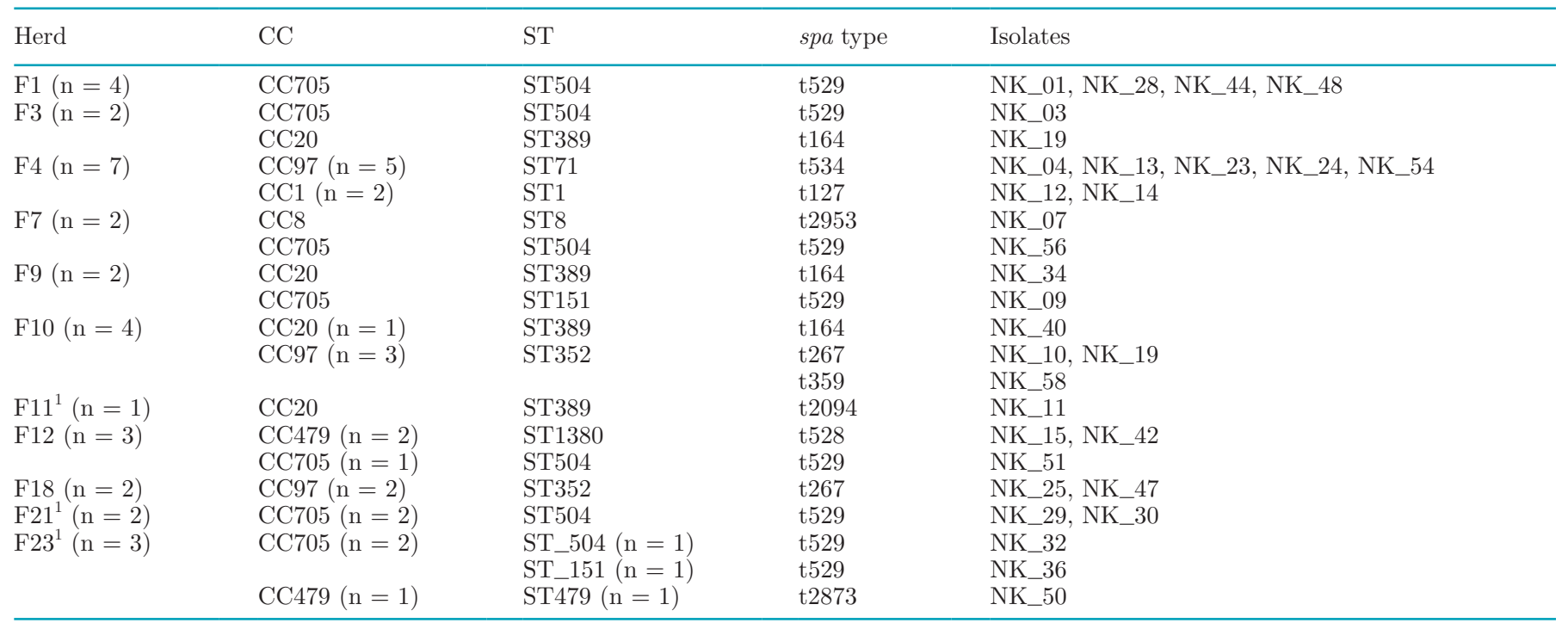

${ }^{1}$ For 3 farms, herd-level problems with Staph. aureus mastitis were known. 
Table 3. Resistance phenotypes and minimum inhibition values determined for 58 Staphylococcus aureus strains isolated from bovine mastitis milk $^{1}$

\begin{tabular}{|c|c|c|c|c|c|c|}
\hline Antimicrobial agent & $\begin{array}{c}\text { Susceptible } \\
(\%)\end{array}$ & $\begin{array}{c}\text { Intermediate } \\
(\%)\end{array}$ & $\begin{array}{c}\text { Resistant } \\
(\%)\end{array}$ & $\mathrm{MIC}_{50}{ }^{2}$ & $\mathrm{MIC}_{90}{ }^{3}$ & Clinical breakpoints applied \\
\hline Penicillin & 86 & - & 14 & 0.125 & 2 & Human clinical breakpoint ${ }^{4}$ \\
\hline Ampicillin & - & - & - & 4 & 4 & - \\
\hline Cefoperazone & - & - & - & 2 & 2 & - \\
\hline Cefquinome & - & - & - & 1 & 1 & - \\
\hline Oxacillin & 98 & - & 2 & 1 & 1 & Human clinical breakpoint ${ }^{4}$ \\
\hline Marbofloxacin & - & - & - & 0.25 & 0.5 & - \\
\hline Amoxicillin/clavulanic acid & - & - & - & $4 / 2$ & $4 / 2$ & - \\
\hline Kanamycin/cefalexin & 100 & - & - & $4 / 0.4$ & $4 / 0.4$ & Human clinical breakpoint ${ }^{4}$ \\
\hline
\end{tabular}

${ }^{1}$ A comprehensive overview of the distribution of MIC is provided in Supplemental Figure S1 (https://doi.org/10.3168/jds.2018-15317).

${ }^{2} \mathrm{MIC}_{50}=$ concentration of antimicrobial agent that inhibits growth of $50 \%$ of all tested strains.

${ }^{3} \mathrm{MIC}_{90}=$ concentration of antimicrobial agent that inhibits growth of $90 \%$ of all tested strains.

${ }^{4}$ For many antimicrobial agents tested, breakpoints for use in cattle are missing. Therefore, human breakpoints were used for classification as susceptible, intermediate, or resistant.

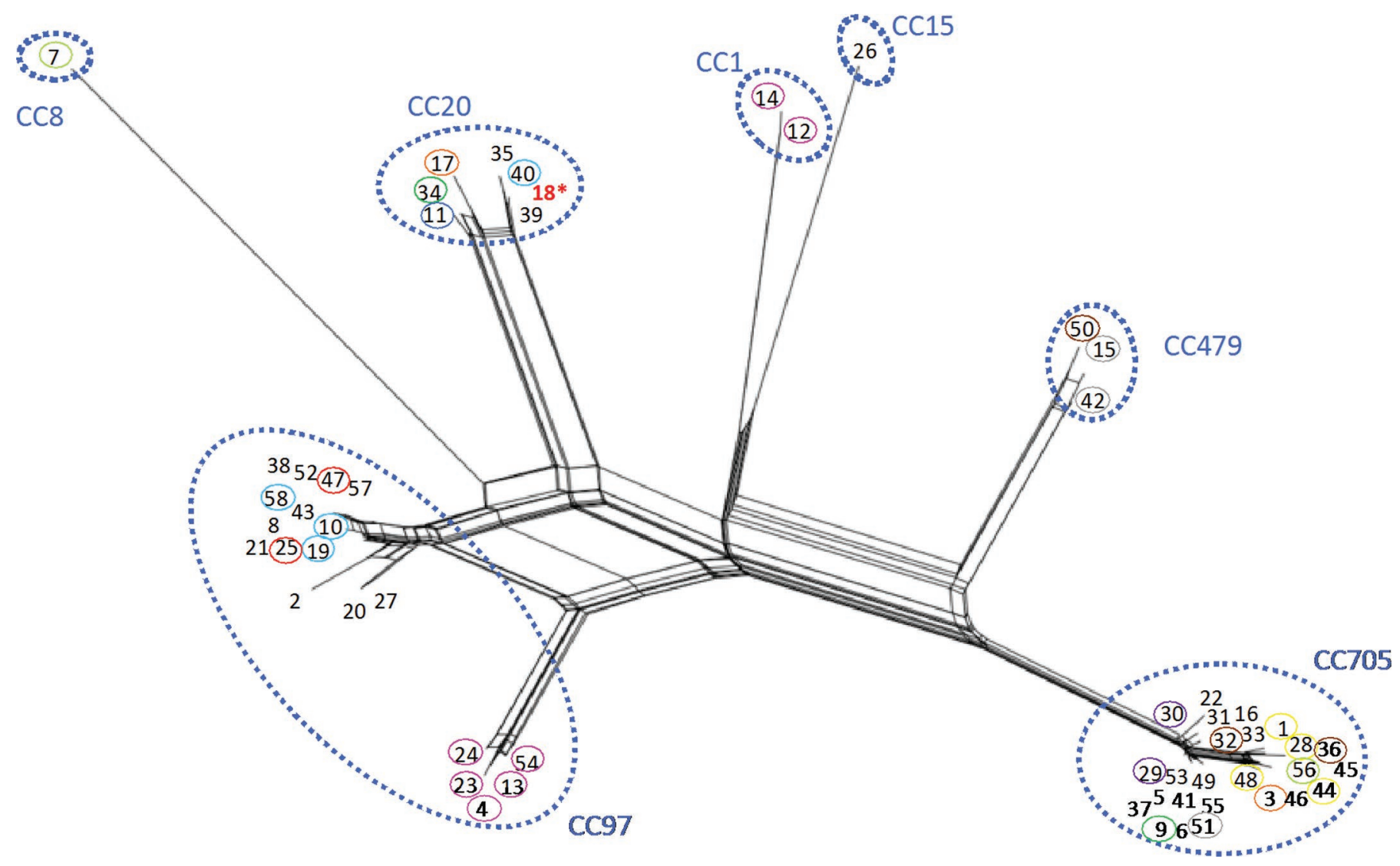

Figure 1. SplitsTree depicting the relatedness of the bovine Staphylococcus aureus strains based on similarity of DNA microarray profiles. Proximity in the unrooted phylogenetic network indicates similarity of DNA hybridization profiles and, thus, relatedness of the respective isolates. All strains assigned to the same clonal complex (CC) formed clusters in the SplitsTree. NK_18 (marked by an asterisk), the strain that exhibited resistance to multiple antimicrobial agents, including oxacillin, clustered very closely to other CC20 isolates of both t2094 and t164 that did not exhibit the same resistance profile. Isolates that originated from the same farm are marked by colored circles (farm F1 $=$ yellow, farm F3 = orange, farm F4 = pink, farm F7 = light green, farm F9 = dark green, farm F10 = light blue, farm F11 = dark blue, farm F12 = gray, farm $\mathrm{F} 18=$ red, farm F21 = purple, farm F23 = brown). 


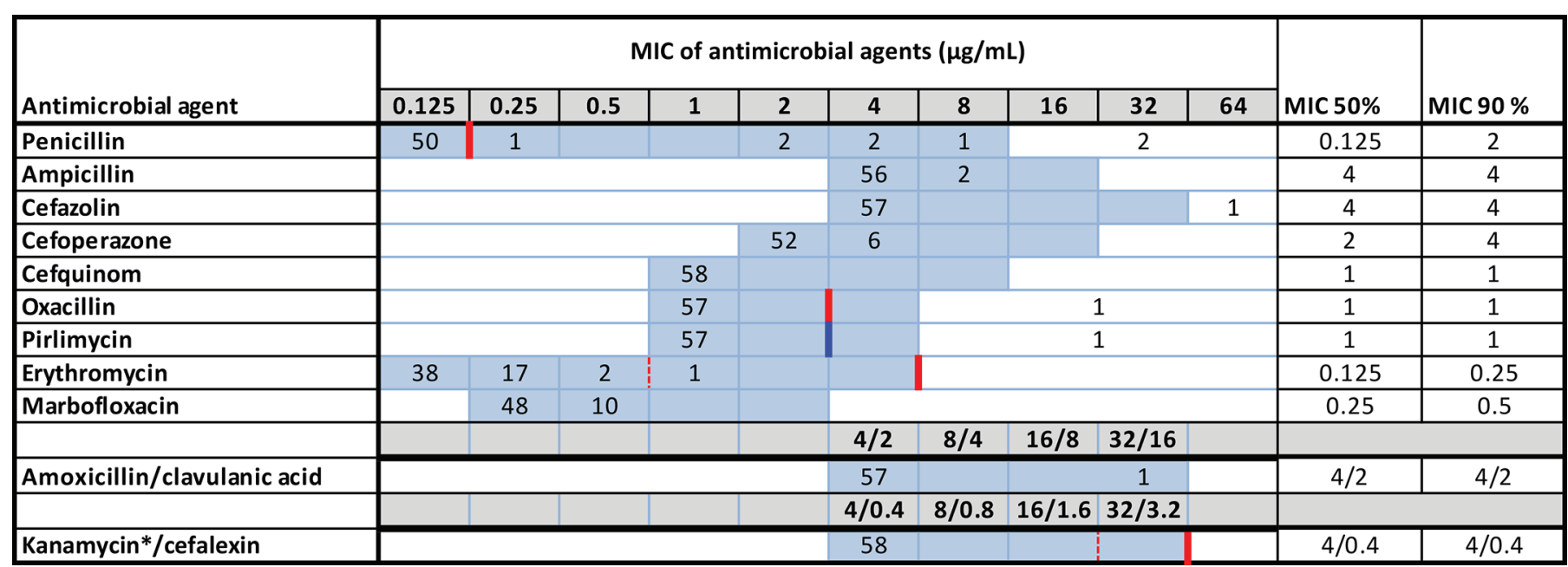

Figure 2. Overview of MIC for the 58 Staphylococcus aureus isolates tested. Numbers indicate the number of strains exhibiting the corresponding MIC value. Light blue areas indicate the tested concentration range on the microdilution plate. Values above this range denote MIC values greater than the highest concentration tested. If available, MIC breakpoints are indicated using vertical lines (red = human breakpoint, blue = bovine breakpoint) separating resistant and susceptible strains, with dotted lines indicating the differentiation between susceptible and intermediate. Breakpoints were obtained from the CLSI guidelines 2017 for human and 2015 for veterinarian breakpoints. MIC $_{50}$ and MIC $_{90}$ represent the concentration of antimicrobial agent inhibiting growth of 50 or $90 \%$ of strains, respectively. In the case of kanamycin/cefalexin, the MIC breakpoint is indicated for kanamycin only (marked by an asterisk).

infective endocarditis (Nethercott et al., 2013), as well as with cases of staphylococcal food poisoning (Suzuki et al., 2014). Interestingly, only 1 of the bovine mastitis isolates was assigned to CC8, which was linked to Staph. aureus of genotype B, associated with high within-herd prevalence of mastitis in cattle (Graber et al., 2009). Clonal complex 8 is also known as pandemic MRSA lineage, with numerous community- and hospital-associated MRSA strains originating from this CC (Monecke et al., 2011). The penicillin-resistant CC8 isolate in our study originated from a cow with chronic mastitis that was part of a herd for which another milk sample harboring a CC705 strain from a cow with subclinical mastitis was submitted. In total, 7 of the 10 herds for which multiple cows were sampled were affected by more than 1 Staph. aureus strain.

The MRSA strains harbor 1 of several staphylococcal cassette chromosome mec (SCCmec) variants. These $\mathrm{SCC} m e c$ are mobile genetic elements that carry mecA/ $m e c C$ coding for penicillin-binding protein 2a (PBP2a), a transpeptidase conferring resistance to all $\beta$-lactam antibiotics except ceftobiprole and ceftaroline. The DNA microarray array used in our study covers not only mecA and mecC, but also various other staphylococcal cassette chromosome-associated markers, such as recombinase genes, fusC, and so on. None of the strains in our study carried mecA or mecC; however, NK_7 (CC8, ST8, t2953) harbored staphylococcal cassette chromosome recombinase genes $\operatorname{crr} A$ and $\operatorname{crr} B$, which enable excision and integration of SCCmec
(Katayama et al., 2000; Wang and Archer, 2010). In addition, strain NK_18 (CC20, ST389, t2094) was classified as resistant to oxacillin, although neither mecA/ mec $C$ nor other staphylococcal cassette chromosomeassociated genes were detected by DNA microarray. It has recently been shown that the commonly known 12 SCC mec types and their variants are only a fraction of the true diversity of SCCmec elements (Monecke et al., 2016, 2018). Therefore, a modification of the respective genomic elements or a variant not covered by the microarray used may be present in NK_18.

Overall, phenotypic antimicrobial resistance among the bovine mastitis strains was low, with only $14 \%$ (n $=8$ ) of strains classified as resistant to penicillin and 1 strain each classified as resistant to oxacillin and pirlimycin. This is consistent with previous studies (Sakwinska et al., 2011b; Moser et al., 2013) that investigated antimicrobial susceptibility in Staph. aureus strains collected from bovine mastitis milk in Switzerland. Previous studies in the United States, Chile, and Europe classified between 2 and $61 \%$ of Staph. aureus tested as resistant to penicillin (Oliver and Murinda, 2012). Although no clinical breakpoints are available for the combination of kanamycin and cefalexin, growth of all strains was inhibited by the lowest combination of kanamycin/cefalexin concentrations tested $(4 \mu \mathrm{g} / \mathrm{mL}$ of kanamycin and $0.4 \mu \mathrm{g} / \mathrm{mL}$ of cefalexin).

We detected the fosfomycin resistance gene, fos $B$, which encodes a metallothiol transferase, in CC8, $\mathrm{CC} 15$, and $\mathrm{CC} 20$. The results are in accordance with a 
previous paper reporting that $f \circ s B$ is specific for certain CC, including CC15 and CC20 (Monecke et al., 2008). In strains of CC705, we also frequently detected the tst gene encoding the toxic shock syndrome toxin, a superantigen causing life-threatening disease characterized by fever, desquamation, rash, multisystem failure, and shock (Fraser and Proft, 2008). We also detected various enterotoxin genes, including genes coding for major enterotoxins SEC and SED, and the enterotoxin gene cluster $(e g c)$. Ingestion of staphylococcal enterotoxins preformed in food leads to staphylococcal food poisoning, resulting in violent vomiting, often accompanied by diarrhea, fever, and prostration (Fetsch and Johler, 2018). Whereas food handlers colonized or infected with Staph. aureus represent the most common source of staphylococcal food poisoning strains (Wattinger et al., 2012), outbreaks have also been linked to consumption of raw milk or raw milk cheese originating from dairy animals suffering of mastitis (Giezendanner et al., 2009; Johler et al., 2015).

It has been argued that knowledge of local epidemiology is essential for antimicrobial treatment choices in the absence of susceptibility data (Sakwinska et al., 2011b). Previous reports indicate that isolates of CC705, CC479, and CC20 are only very rarely classified as resistant to antimicrobial agents used to treat bovine mastitis (Sakwinska et al., 2011b; Moser et al., 2013). In our study, all CC705 and CC479 strains were susceptible to all antimicrobial agents tested. The same was true for NK_11, a CC20 (ST389/t2094) strain associated with herd problems with Staph. aureus mastitis, but not for the other CC20 strains, indicating the onset of new resistance patterns. In addition, NK_18, the strain exhibiting resistance to most antimicrobial agents, was assigned to CC20 (ST389/t2094).

Thus, our findings stress the crucial need for susceptibility testing before selecting antimicrobial agents for treatment of bovine mastitis, even though the local distribution of lineages may be well known. In addition, further veterinary clinical breakpoints are urgently needed to allow for accurate susceptibility classification and to improve therapeutic recommendations.

\section{REFERENCES}

Aires-de-Sousa, M., K. Boye, H. de Lencastre, A. Deplano, M. C. Enright, J. Etienne, A. Friedrich, D. Harmsen, A. Holmes, X. W. Huijsdens, A. M. Kearns, A. Mellman, H. Meugnier, J. K. Rasheed, E. Spalburg, B. Strommenger, M. J. Struelens, F. C. Tenover, J. Thomas, U. Vogel, H. Westh, J. Xu, and W. Witte. 2006. High interlaboratory reproducibility of DNA sequence-based typing of bacteria in a multicenter study. J. Clin. Microbiol. 44:619-621.

Boss, R., A. Cosandey, M. Luini, K. Artursson, M. Bardiau, F. Breitenwieser, E. Hehenberger, T. Lam, M. Mansfeld, A. Michel, G. Mösslacher, J. Naskova, S. Nelson, O. Podpečan, A. Raemy, E. Ryan, O. Salat, P. Zangerl, A. Steiner, and H. U. Graber. 2016. Bovine Staphylococcus aureus: Subtyping, evolution, and zoonotic transfer. J. Dairy Sci. 99:515-528. https://doi.org/10.3168/jds .2015-9589.

Ellington, M. J., L. Yearwood, M. Ganner, C. East, and A. M. Kearns. 2008. Distribution of the ACME- $\operatorname{arcA}$ gene among methicillin-resistant Staphylococcus aureus from England and Wales. J. Antimicrob. Chemother. 61:73-77. https://doi.org/10.1093/jac/dkm422.

Enright, M. C., N. P. J. Day, C. E. Davies, S. J. Peacock, and B. G. Spratt. 2000. Multilocus sequence typing for characterization of methicillin-resistant and methicillin-susceptible clones of Staphylococcus aureus. J. Clin. Microbiol. 38:1008-1015.

Fetsch, A., and S. Johler. 2018. Staphylococcus aureus as a foodborne pathogen. Curr. Clin. Microbiol. Rep. 5:88-96. https://doi.org/10 .1016/B978-0-12-809671-0.00001-2.

Fitzgerald, J. R. 2012. Livestock-associated Staphylococcus aureus: origin, evolution and public health threat. Trends Microbiol. 20:192198. https://doi.org/10.1016/j.tim.2012.01.006.

Fluit, A. C. 2012. Livestock-associated Staphylococcus aureus. Clin. Microbiol. Infect. 18:735-744. https://doi.org/10.1111/j.1469-0691 .2012.03846.x.

Fraser, J. D., and T. Proft. 2008. The bacterial superantigen and superantigen-like proteins. Immunol. Rev. 225:226-243. https://doi .org/10.1111/j.1600-065X.2008.00681.x.

Giezendanner, N., B. Meyer, M. Gort, P. Müller, and C. Zweifel. 2009. Raw milk-associated Staphylococcus aureus intoxication in children. Schweiz. Arch. Tierheilkd. 151:329-331. https://doi.org/10 .1024/0036-7281.151.7.329.

Graber, H. U., J. Naskova, E. Studer, T. Kaufmann, M. Kirchhofer, M. Brechbühl, W. Schaeren, A. Steiner, and C. Fournier. 2009. Mastitis-related subtypes of bovine Staphylococcus aureus are characterized by different clinical properties. J. Dairy Sci. 92:1442-1451. https://doi.org/10.3168/jds.2008-1430.

Harmsen, D., H. Claus, W. Witte, J. Rothgänger, H. Claus, D. Turnwald, and U. Vogel. 2003. Typing of methicillin-resistant Staphylococcus aureus in a university hospital setting by using novel software for spa repeat determination and database management. J. Clin. Microbiol. 41:5442-5448. https://doi.org/10.1128/JCM.41 .12 .5442

Hasman, H., A. Moodley, L. Guardabassi, M. Stegger, R.L. Skov, and F.M. Aarestrup. 2010. spa type distribution in Staphylococcus aureus originating from pigs, cattle and poultry. Vet. Microbiol. 141:326-331. https://doi.org/10.1016/j.vetmic.2009.09.025.

Huson, D.H., and D. Bryant. 2006. Application of phylogenetic networks in evolutionary studies. Mol. Biol. Evol. 23:254-267. https:/ /doi.org/10.1093/molbev/msj030.

Johler, S., F. Layer, and R. Stephan. 2011. Comparison of virulence and antibiotic resistance genes of food poisoning outbreak isolates of Staphylococcus aureus with isolates obtained from bovine mastitis milk and pig carcasses. J. Food Prot. 74:1852-1859. https://doi .org/10.4315/0362-028X.JFP-11-192.

Johler, S., D. Weder, C. Bridy, M. C. Huguenin, L. Robert, J. Hummerjohann, and R. Stephan. 2015. Outbreak of Staphylococcal food poisoning among children and staff at a Swiss boarding school due to soft cheese made from raw milk. J. Dairy Sci. 98:2944-2948.

Katayama, Y., T. Ito, and K. Hiramatsu. 2000. A new class of genetic element, staphylococcus cassette chromosome mec, encodes methicillin resistance in Staphylococcus aureus. Antimicrob. Agents Chemother. 44:1549-1555. https://doi.org/10.1128/AAC.44.6.1549 -1555.2000 .

Klein, R. C., M. H. Fabres-Klein, M. A. V. P. Brito, L. G. Fietto, and A. D. O. B. Ribon. 2012. Staphylococcus aureus of bovine origin: Genetic diversity, prevalence and the expression of adhesinencoding genes. Vet. Microbiol. https://doi.org/10.1016/j.vetmic 2012.05.025.

Luedicke, C., P. Slickers, R. Ehricht, and S. Monecke. 2010. Molecular fingerprinting of Staphylococcus aureus from bone and joint infections. Eur. J. Clin. Microbiol. Infect. Dis. 29:457-463. https://doi .org/10.1007/s10096-010-0884-4.

Monecke, S., G. Coombs, A.C. Shore, D.C. Coleman, P. Akpaka, H. Chow, M. Ip, L. Jatzwauk, D. Jonas, K. Kadlec, A. Kearns, F. Laurent, F.G.O. Brien, J. Pearson, A. Ruppelt, S. Schwarz, P. Slickers, H. Tan, S. Weber, and R. Ehricht. 2011. A field guide 
to pandemic, epidemic and sporadic clones of methicillin-resistant Staphylococcus aureus. PLoS One 6:e17936. https://doi.org/10 .1371/journal.pone.0017936.

Monecke, S., L. Jatzwauk, E. Müller, H. Nitschke, K. Pfohl, P. Slickers, A. Reissig, A. Ruppelt-Lorz, and R. Ehricht. 2016. Diversity of SCCmec elements in Staphylococcus aureus as observed in south-eastern Germany. PLoS One 11:e0162654. https://doi.org/ 10.1371/journal.pone.0162654

Monecke, S., P. Slickers, and R. Ehricht. 2008. Assignment of Staphylococcus aureus isolates to clonal complexes based on microarray analysis and pattern recognition. FEMS Immunol. Med. Microbiol. 53:237-251. https://doi.org/10.1111/j.1574-695X.2008.00426.x.

Monecke, S., P. Slickers, D. Gawlik, E. Müller, A. Reissig, A. RuppeltLorz, S. C. de Jäckel, A. T. Feßler, M. Frank, H. Hotzel, K. Kadlec, L. Jatzwauk, I. Loncaric, S. Schwarz, K. Schlotter, A. Thürmer, S. Wendlandt, and R. Ehricht. 2018. Variability of SCCmec elements in livestock-associated CC398 MRSA. Vet. Microbiol. 217:36-46.

Moser, A., R. Stephan, S. Corti, and S. Johler. 2013. Comparison of genomic and antimicrobial resistance features of latex agglutination test-positive and latex agglutination test-negative Staphylococcus aureus isolates causing bovine mastitis. J. Dairy Sci. 96:329-334. https://doi.org/10.3168/jds.2012-5944.

National Mastitis Council. 1999. Laboratory Handbook on Bovine Mastitis. NMC, Verona, WI

Neave, F. K., F. H. Dodd, R. G. Kingwill, and D. R. Westgarth. 1969. Control of mastitis in the dairy herd by hygiene and management. J. Dairy Sci. 52:696-707. https://doi.org/10.3168/jds.S0022 -0302(69)86632-4.

Nethercott, C., A. N. Mabbett, M. Totsika, P. Peters, J. C. Ortiz, G. R. Nimmo, G. W. Coombs, M. J. Walker, and M. A. Schembri. 2013. Molecular characterization of endocarditis-associated Staphylococcus aureus. J. Clin. Microbiol. 51:2131-2138. https:// doi.org/10.1128/JCM.00651-13.

Oliver, S. P., and S. E. Murinda. 2012. Antimicrobial resistance of mastitis pathogens. Vet. Clin. North Am. Food Anim. Pract. $28: 165-185$.

Peton, V., and Y. Le Loir. 2014. Staphylococcus aureus in veterinary medicine. Infect. Genet. Evol. 21:602-615. https://doi.org/10 .1016/j.meegid.2013.08.011.

Saini, V., J. T. McClure, D. T. Scholl, T. J. DeVries, and H. W. Barkema. 2012. Herd-level association between antimicrobial use and antimicrobial resistance in bovine mastitis Staphylococcus au- reus isolates on Canadian dairy farms. J. Dairy Sci. 95:1921-1929. https://doi.org/10.3168/jds.2011-5065.

Sakwinska, O., M. Giddey, M. Moreillon, D. Morisset, A. Waldvogel, and P. Moreillon. 2011a. Staphylococcus aureus host range and human-bovine host shift. Appl. Environ. Microbiol. 77:5908-5915. https://doi.org/10.1128/AEM.00238-11.

Sakwinska, O., D. Morisset, J.-Y. Madec, A. Waldvogel, P. Moreillon, and M. Haenni. 2011b. Link between genotype and antimicrobial resistance in bovine mastitis-related Staphylococcus aureus strains, determined by comparing Swiss and French isolates from the Rhône Valley. Appl. Environ. Microbiol. 77:3428-3432. https:/ /doi.org/10.1128/AEM.02468-10.

Schreiner, D. A., and P. L. Ruegg. 2003. Relationship between udder and leg hygiene scores and subclinical mastitis. J. Dairy Sci 86:3460-3465. https://doi.org/10.3168/jds.S0022-0302(03)73950 -2 .

Stalder, U., R. Stephan, S. Corti, M. Bludau, A. Maeschli, P. Klocke, and S. Johler. 2014. Short communication: Staphylococcus aureus isolated from colostrum of dairy heifers represent a closely related group exhibiting highly homogeneous genomic and antimicrobial resistance features. J. Dairy Sci. 97:4997-5000. https://doi.org/10 .3168/jds.2013-7721.

Steeneveld, W., T. van Werven, H. W. Barkema, and H. Hogeveen. 2011. Cow-specific treatment of clinical mastitis: An economic approach. J. Dairy Sci. 94:174-188. https://doi.org/10.3168/jds.2010 -3367 .

Suzuki, Y., K. Omoe, D. L. Hu, Y. Sato'o, H. K. Ono, C. Monma, T. Arai, N. Konishi, R. Kato, A. Hirai, A. Nakama, A. Kai, and Y. Kamata. 2014. Molecular epidemiological characterization of Staphylococcus aureus isolates originating from food poisoning outbreaks that occurred in Tokyo, Japan. Microbiol. Immunol. 58:570-580. https://doi.org/10.1111/1348-0421.12188.

Wang, L., and G. L. Archer. 2010. Roles of CcrA and CcrB in excision and integration of staphylococcal cassette chromosome mec, a Staphylococcus aureus genomic island. J. Bacteriol. 192:3204-3212. https://doi.org/10.1128/JB.01520-09.

Wattinger, L., R. Stephan, F. Layer, and S. Johler. 2012. Comparison of Staphylococcus aureus isolates associated with food intoxication with isolates from human nasal carriers and human infections. Eur. J. Clin. Microbiol. Infect. Dis. 31:455-464.

Wells, S. J., S. L. Ott, and A. H. Seitzinger. 1998. Key health issues for dairy cattle-New and old. J. Dairy Sci. 81:3029-3035. 